\title{
Effect of Yttrium Addition on Thermal Stability and Glass Forming Ability in Fe-TM (Mn, Mo, Ni)-B Ternary Alloys
}

\author{
Ji-Hun Kim ${ }^{1}$, Joon Sik Park ${ }^{1}$, Eric Fleury ${ }^{2}$, Won Tae Kim ${ }^{3}$ and Do Hyang Kim ${ }^{1, *}$ \\ ${ }^{1}$ Center for Non-crystalline Materials, Department of Metallurgical Engineering, Yonsei University, Seoul 120-749, Korea \\ ${ }^{2}$ Advanced Metals Research Center, Korea Institute of Science and Technology, Seoul 130-650, Korea \\ ${ }^{3}$ Applied Science Division, Cheongju University, Cheongju 360-764, Korea
}

The effect of $\mathrm{Y}$ addition on the glass forming ability (GFA) of in $\mathrm{Fe}_{70} \mathrm{TM}(\mathrm{TM}=\mathrm{Mn}, \mathrm{Mo}, \mathrm{Ni})_{13} \mathrm{~B}_{17}$ alloys have been examined in the present study. Substitution of 3-10 at $\% \mathrm{Fe}$ with $\mathrm{Y}$ improves the GFA. $\mathrm{Fe}_{70-x} \mathrm{Mn}_{13} \mathrm{~B}_{17} \mathrm{Y}_{x}(x=5)$ and $\mathrm{Fe}_{70-x} \mathrm{Mo}_{13} \mathrm{~B}_{17} \mathrm{Y}_{x}(x=3)$ alloys exhibit high $T_{\text {rg }}$ $\left(=T_{\mathrm{g}} / T_{\mathrm{l}}\right)(>0.55)$ and $\gamma\left(=T_{\mathrm{x}} /\left[T_{1}+T_{\mathrm{g}}\right]\right)(>0.37)$ values enabling fabrication of $1 \mathrm{~mm}$ diameter bulk metallic glass. The GFA improves when addition of $\mathrm{Y}$ decreases the melting temperature, and, at the same time, increases the crystallization onset temperature. Extended Kissinger analysis of the DSC data indicates that a kinetic boundary condition for the formation of the amorphous phase widens by addition of Y.

(Received March 22, 2004; Accepted July 7, 2004)

Keywords: iron based bulk metallic glass, yttrium, glass forming ability

\section{Introduction}

Recently, many new alloy systems requiring a relatively low critical cooling rate $(<100 \mathrm{~K} / \mathrm{s})$ for glass formation have been developed, enabling the fabrication of large size bulk metallic glass (BMG) components. ${ }^{1,2)}$ Since the 1980's, Febased glassy alloys have been extensively developed for magnetic and structural applications. ${ }^{3-6)}$ For the Fe-based glassy alloys exhibiting a relatively large glass forming ability (GFA) such as Fe-TM (Transition Metal)-B alloy systems, ${ }^{2,5)}$ it has been generally known that the addition of metalloid elements such as B, C and P up to 20 at\% is necessary for the enhancement of GFA. Recently, it has been reported that small addition of $\mathrm{Y}$ in multi-component $\mathrm{Fe}-\mathrm{Zr}$ Mo-Co-Al-Cr-B glassy alloys can improve the GFA by an oxygen scavenging effect through the formation of yttrium oxide in the alloy melt, thereby suppressing the heterogeneous nucleation. ${ }^{7)}$ The previous result ${ }^{7)}$ indicates that the effect of addition of Y in Fe-TM-B alloy system needs to be more systematically investigated.

Therefore, in the present study, effect of small addition of $\mathrm{Y}$ has been investigated in the $\mathrm{Fe}-\mathrm{TM}(\mathrm{TM}=\mathrm{Mn}, \mathrm{Mo}, \mathrm{Ni})-\mathrm{B}$ ternary systems. The heats of mixing in the Fe-Y and B-Y binary systems are $-1 \mathrm{~kJ} / \mathrm{mol}$ and $-35 \mathrm{~kJ} / \mathrm{mol},{ }^{8)}$ respective$1 \mathrm{y}$, and the atomic size of $\mathrm{Y}\left(1.82 \times 10^{-10} \mathrm{~m}\right)$ is larger than those of Fe $\left(1.24 \times 10^{-10} \mathrm{~m}\right)$ and $\mathrm{B}\left(0.9 \times 10^{-10} \mathrm{~m}\right)$, which is believed to be favorable for the increase of the packing density of the amorphous phase, thus improving the glass forming ability. To investigate the effect of $\mathrm{Y}, \mathrm{Fe}$ was replaced with Y. To keep the Fe content $>60$ at $\%$, the content of TM and B were fixed at 13 at $\%$ and 17 at $\%$, respectively. In binary Fe-B system, eutectic reaction occurs at the composition of $17 \mathrm{at} \%$ B. To examine the validity of above hypothesis, we performed next experiments. First, variations of the glass transition temperature, the crystallization temperature and the melting temperature with $\mathrm{Y}$ addition were studied by thermal analysis in melt-spun $\mathrm{Fe}_{70-x} \mathrm{TM}(\mathrm{TM}=\mathrm{Mn}, \mathrm{Mo}, \mathrm{Ni})_{13} \mathrm{~B}_{17} \mathrm{Y}_{x}(x=0,3,5,10)$ alloys.

*Corresponding author, E-mail: dohkim@yonsei.ac.kr
Secondly, to examine the GFA bulk glassy samples were prepared by injection casting method.

\section{Experimental}

Alloy ingots with compositions of $\mathrm{Fe}_{70-x} \mathrm{TM}(\mathrm{TM}=\mathrm{Mn}$, Mo, Ni ${ }_{13} \mathrm{~B}_{17} \mathrm{Y}_{x}(x=0,3,5,10$ at $\%)$ were produced by arc melting of high purity elemental components. Melting operations have been repeated 3-4 times for the purpose of homogeneous distribution of the components. Rod type ingots were produced by injection casting into copper mold with diameters of 1 and $2 \mathrm{~mm}$ under a purified Ar gas atmosphere. For comparison, amorphous ribbons of each composition with a cross section of about $0.025 \times 1 \mathrm{~mm}^{2}$ were also produced by the melt spinning technique under Ar atmosphere.

The presence of amorphous or crystalline phases was identified by X-ray diffraction (XRD, Rigaku CN-2301 X-ray diffractometer). The microstructural analysis was performed using optical microscopy and scanning electron microscopy (SEM, Hitachi S-2700) equipped with energy-dispersive spectroscopy (EDS). The thermal stability of the amorphous phase (glass transition and crystallization) was investigated using differential scanning calorimetry (DSC, Perkin-Elmer DSC7) during heating at various heating rates between 0.083 and $0.677 \mathrm{~K} / \mathrm{s}$. The onset and termination of the melting were measured by differential thermal analysis (DTA, PerkinElmer DTA7) during heating at a rate of $0.333 \mathrm{~K} / \mathrm{s}$.

\section{Results}

\section{1 $\mathrm{Fe}_{70-x} \mathrm{Mn}_{13} \mathrm{~B}_{17} \mathrm{Y}_{x}$ alloy ribbons}

Figure 1(a) shows the DTA traces obtained from the meltspun $\mathrm{Fe}_{70-x} \mathrm{Mn}_{13} \mathrm{~B}_{17} \mathrm{Y}_{x}(x=0,3,5$ and 10) alloy ribbons during heating with a rate of $0.33 \mathrm{~K} / \mathrm{s}$. The alloy of $x=0$ did not show glass transition or crystallization reaction in the DTA traces. But with increasing $x$, the glass transition followed by three or four exothermic reactions due to crystallization appeared in the alloys with $x=3$ and 5, and then disappeared again at $x=10$. The DSC traces shown in Figs. 2(a) and (b) also show the glass transition and the first crystalliza- 

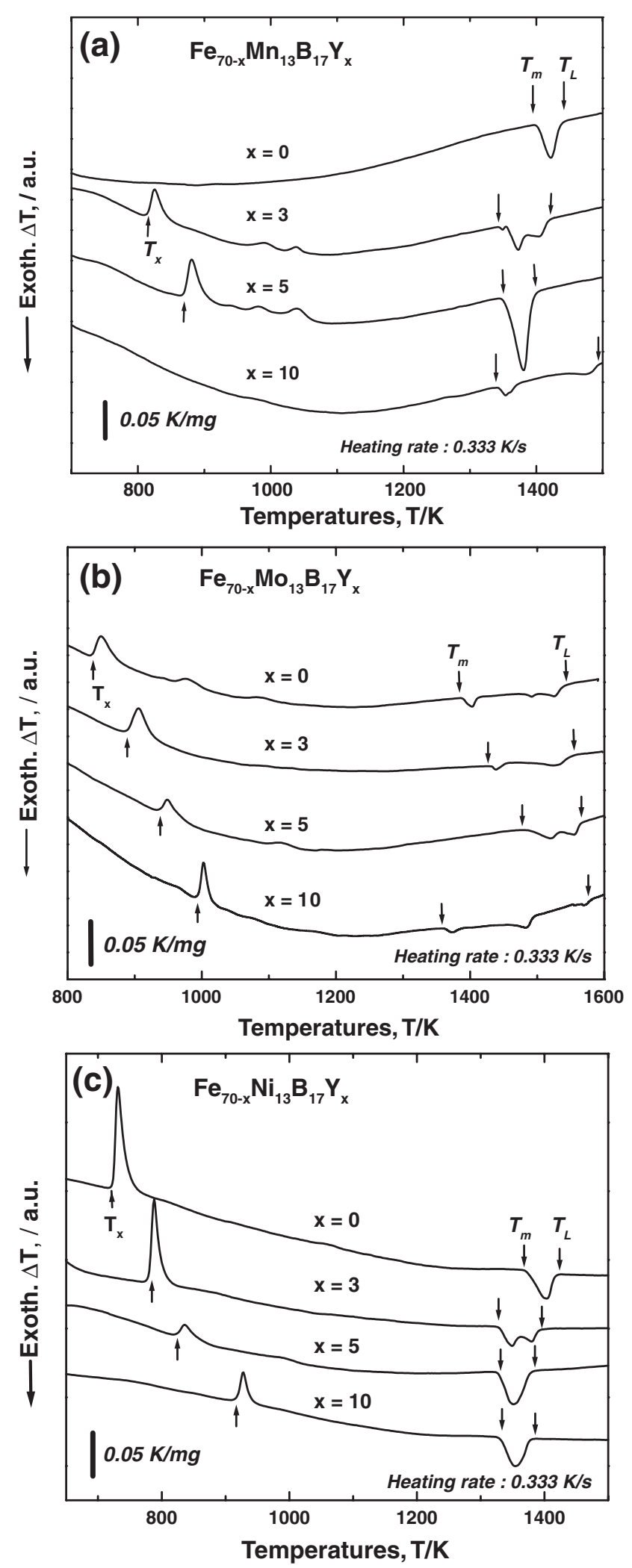

Fig. 1 DTA traces taken from the $\mathrm{Fe}_{70-x} \mathrm{TM}(\mathrm{Mn}, \mathrm{Mo}, \mathrm{Ni}){ }_{13} \mathrm{~B}_{17} \mathrm{Y}_{x}(x=0$, 3,5 and 10) alloy melt spun ribbons with heating rate of $0.33 \mathrm{~K} / \mathrm{s}$. (a) $\mathrm{Fe}_{70-x} \mathrm{Mn}_{13} \mathrm{~B}_{17} \mathrm{Y}_{x}$ alloys, (b) $\mathrm{Fe}_{70-x} \mathrm{Mo}_{13} \mathrm{~B}_{17} \mathrm{Y}_{x}$ alloys (c) $\mathrm{Fe}_{70-x} \mathrm{Ni}_{13}-$ $\mathrm{B}_{17} \mathrm{Y}_{x}$ alloys.

tion reaction in the alloys, $x=3$ and 5, during heating with a rate of $0.667 \mathrm{~K} / \mathrm{s}$. The glass transition $\left(T_{\mathrm{g}}\right)$ and crystallization onset temperatures $\left(T_{\mathrm{x}}\right)$ are marked by arrows in the DTA and DSC traces. The $T_{\mathrm{g}}$ and $T_{\mathrm{x}}$ increased from $779 \mathrm{~K}$ and $828 \mathrm{~K}$ at

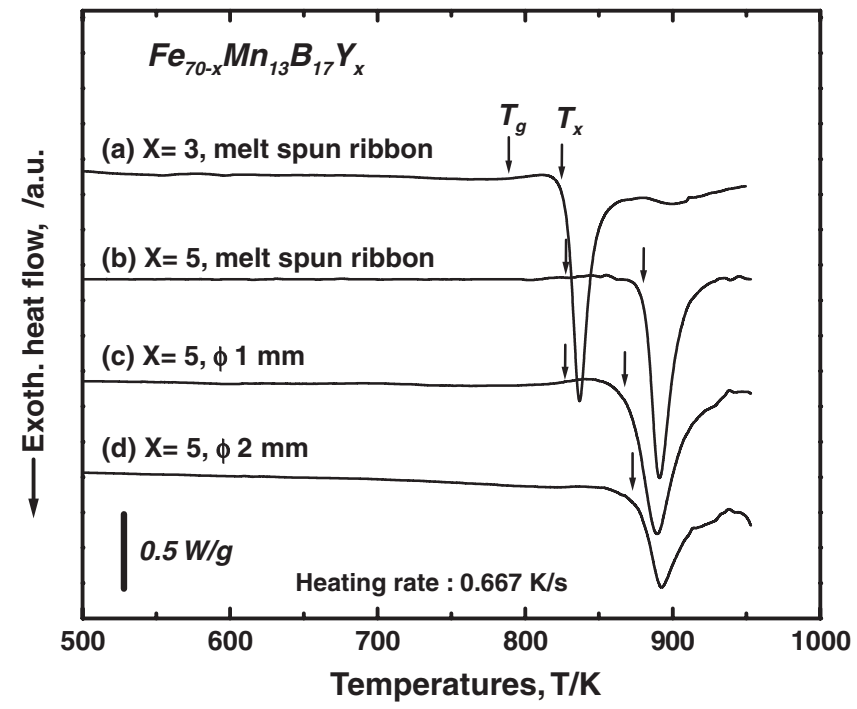

Fig. 2 DSC traces taken from the various samples in $\mathrm{Fe}_{70-x} \mathrm{Mn}_{13} \mathrm{~B}_{17} \mathrm{Y}_{x}$ alloys ( $x=3,5$ at\%). The samples are; (a) and (b) melt spun alloy ribbons of $x=3$ and 5, respectively, (c) and (d) copper mold injected cylindrical samples with $1 \mathrm{~mm}$ and $2 \mathrm{~mm}$ in diameters, respectively $(x=5)$.

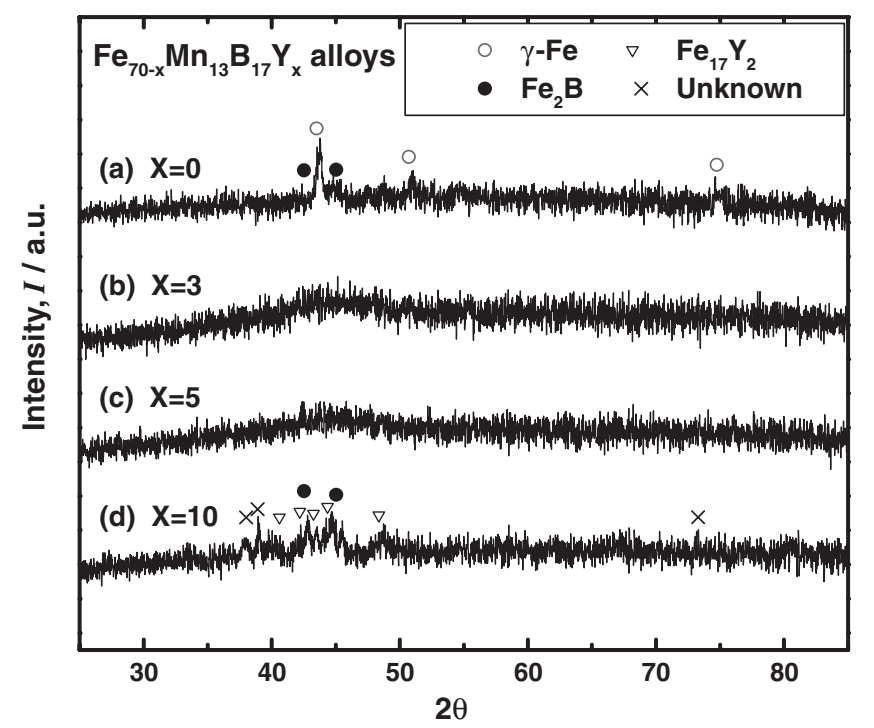

Fig. 3 XRD patterns taken from the melt-spun ribbons in $\mathrm{Fe}_{70-x} \mathrm{Mn}_{13}$ $\mathrm{B}_{17} \mathrm{Y}_{x}(x=0,3,5$ and 10) alloys. (a) $x=0$, (b) $x=3$, (c) $x=5$ and (d) $x=10$.

$x=3$ to $834 \mathrm{~K}$ and $884 \mathrm{~K}$ at $x=5$ in the DSC traces. The onset and termination temperatures of the melting were designated by $T_{\mathrm{m}}$ and $T_{\mathrm{L}}$ in the DTA traces. The $T_{\mathrm{m}}$ decreased with increasing Y content from $x=0$ to 10 . The $T_{\mathrm{L}}$ decreased with increasing $x$ up to $x=5$, then sharply increased at $x=10$. Therefore, the minimum $T_{\mathrm{L}}=1394 \mathrm{~K}$ was observed at $x=5$.

The XRD patterns obtained from the melt-spun alloys with $x=0,3,5$ and 10 are shown in Fig. 3. As expected from the DSC and DTA analyses, the XRD patterns from the meltspun alloys with $x=3$ and 5 showed a diffused halo peak characteristic of an amorphous phase. The XRD pattern from the melt-spun alloy with $x=0$ showed sharp crystalline peaks from $\gamma$-Fe and $\mathrm{Fe}_{2} \mathrm{~B}$, while that from the melt-spun alloy with $x=10$ showed sharp crystalline peaks from $\mathrm{Fe}_{2} \mathrm{~B}$, $\mathrm{Fe}_{17} \mathrm{Y}_{2}$ and unidentified phases. 


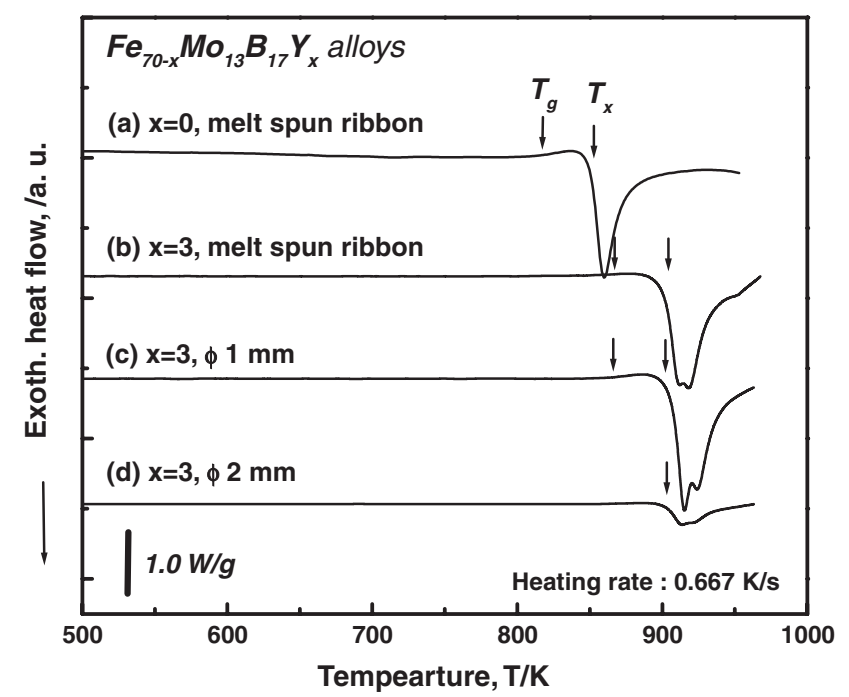

Fig. 4 DSC traces taken from the various samples in $\mathrm{Fe}_{70-x} \mathrm{Mo}_{13} \mathrm{~B}_{17} \mathrm{Y}_{x}$ alloys $(x=0,3$ at $\%)$. The samples are; (a) and (b) melt spun alloy ribbons of $x=0$ and 3, respectively, (c) and (d) copper mold injected cylindrical samples with $1 \mathrm{~mm}$ and $2 \mathrm{~mm}$ in diameters, respectively $(x=3)$.

\section{2 $\mathrm{Fe}_{70-x} \mathrm{Mo}_{13} \mathrm{~B}_{17} \mathrm{Y}_{x}$ alloy ribbons}

Figure 1(b) shows DTA traces taken from the melt-spun $\mathrm{Fe}_{70-x} \mathrm{Mo}_{13} \mathrm{~B}_{17} \mathrm{Y}_{x}(x=0,3,5$ and 10$)$ alloy ribbons. All the DTA traces exhibited exothermic peaks due to crystallization followed by endotherms due to melting events. However, as can be seen clearly in the DSC traces (Figs. 4(a) and (b)), only two alloys ( $x=0$ and 3$)$ exhibited glass transition at $822 \mathrm{~K}$ and $861 \mathrm{~K}$, respectively. The $T_{\mathrm{x}}$ continuously increased from $850 \mathrm{~K}$ at $x=0$ to $1006 \mathrm{~K}$ at $x=10$. The $T_{\mathrm{m}}$ increased with increasing $x$ up to $x=5$, and then decreased sharply at $x=10$. The $T_{\mathrm{L}}$ increased gradually with increasing $x$ up to $x=10$. Therefore, the minimum $T_{\mathrm{L}}=1541 \mathrm{~K}$ was observed at $x=0$. As expected from the DSC and DTA analyses, the XRD patterns obtained form the melt-spun alloys with $x=0,3,5,10$ (not shown) showed a diffuse halo peak characteristic of the amorphous phase.

\section{3 $\mathrm{Fe}_{70-x} \mathrm{Ni}_{13} \mathrm{~B}_{17} \mathrm{Y}_{x}$ alloys}

Figure 1(c) shows DTA traces taken from the melt-spun $\mathrm{Fe}_{70-x} \mathrm{Ni}_{13} \mathrm{~B}_{17} \mathrm{Y}_{x}(x=0,3,5$ and 10) alloy ribbons. Although all the DTA traces exhibited an exothermic peak due to crystallization and an endothermic peak due to melting, no glass transition behavior was observed in DSC traces taken from the melt-spun alloys as shown in Figs. 5(a) and (b). The crystallization onset temperature continuously increased from $736 \mathrm{~K}$ at $x=0$ to $931 \mathrm{~K}$ at $x=10$. The $T_{\mathrm{m}}$ decreased with increasing $x$ from 0 to 3 , and then increased slightly with increasing $x$ up to 10 . The $T_{\mathrm{L}}$ decreased gradually with increasing $x$ from 0 to 10 . Therefore, the minimum $T_{\mathrm{L}}=1378 \mathrm{~K}$ was observed at $x=10$. In particular, a single endotherm was observed in the alloys with $x=5$ and 10 , indicating that the alloy compositions were near pseudoeutectic composition. The XRD patterns obtained form the melt-spun alloys with $x=0,3,5,10$ (not shown) showed a diffuse halo peak characteristic of the amorphous phase.

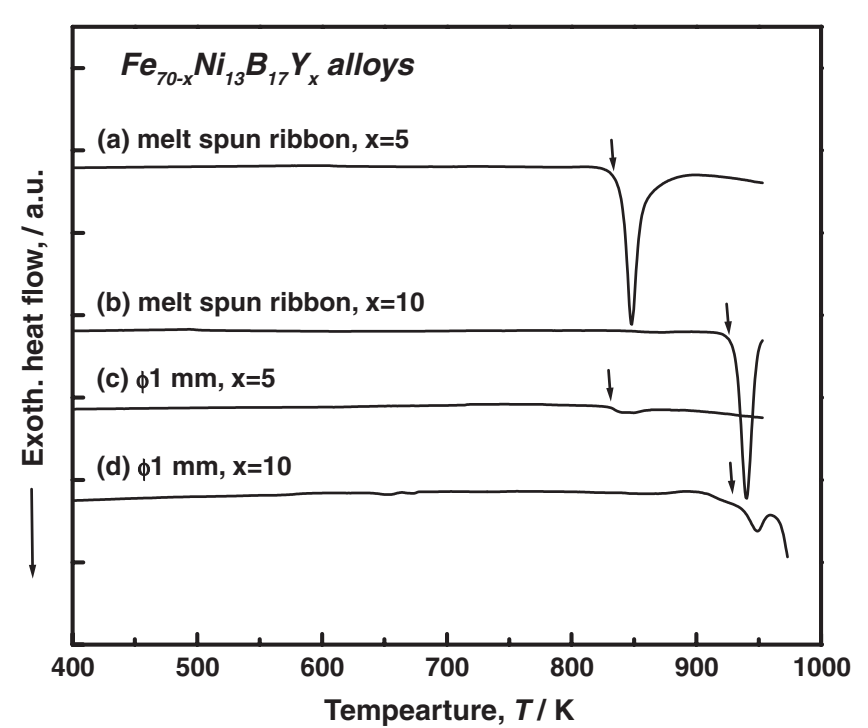

Fig. 5 DSC traces taken from the various samples in $\mathrm{Fe}_{70-x} \mathrm{Ni}_{13} \mathrm{~B}_{17} \mathrm{Y}_{x}$ alloys $(x=5,10$ at $\%)$. The samples are; (a) and (b) melt spun alloy ribbons of $x=5$ and 10, respectively, (c) and (d) injection-cast alloys $(x=5,10$, respectively) samples with $1 \mathrm{~mm}$ in diameters.

Table 1 Thermodynamics and index parameters estimated for glass forming ability of Fe-TM (Mn, Mo, Ni)-B-Y-alloy ribbons.

\begin{tabular}{cccccccccc}
\hline $\mathrm{Fe}_{70-x}$ & $Y$ & $T_{\mathrm{g}}$ & $T_{\mathrm{x}}$ & $\Delta T_{\mathrm{x}}$ & $T_{\mathrm{m}}$ & $T_{\mathrm{L}}$ & $T_{\mathrm{rg}}$ & $\gamma$ & $T_{\mathrm{x}} / T_{\mathrm{L}}$ \\
$\mathrm{TM}_{13} \mathrm{~B}_{17} \mathrm{Y}_{x}$ & at $\%$ & {$[\mathrm{~K}]$} & {$[\mathrm{K}]$} & & {$[\mathrm{K}]$} & {$[\mathrm{K}]$} & & \\
\hline \multirow{3}{*}{$\mathrm{Mn}$} & 0 & - & - & - & 1402.1 & 1437 & - & & - \\
& 3 & 779 & 828 & 49 & 1355 & 1418 & 0.549 & 0.377 & 0.584 \\
& 5 & 834.4 & 884 & 49.6 & 1355 & 1394 & 0.599 & 0.397 & 0.630 \\
& 10 & - & - & - & 1333.7 & 1495 & - & - & - \\
\hline \multirow{2}{*}{$\mathrm{Mo}$} & 0 & 822.3 & 850.2 & 27.9 & 1389.6 & 1541.3 & 0.534 & 0.360 & 0.552 \\
& 3 & 860.8 & 901.3 & 40.5 & 1430 & 1554 & 0.554 & 0.373 & 0.580 \\
& 5 & - & 944.9 & - & 1487 & 1565.9 & - & & 0.603 \\
& 10 & - & 1005.6 & - & 1361.5 & 1597.5 & - & & 0.629 \\
\hline \multirow{2}{*}{$\mathrm{Ni}$} & 0 & - & 735.9 & - & 1374.3 & 1418 & - & & 0.519 \\
& 3 & - & 791.5 & - & 1328.6 & 1390.4 & - & & 0.569 \\
& 5 & - & 840 & - & 1329.4 & 1380 & - & & 0.609 \\
& 10 & - & 931 & - & 1331.1 & 1377.8 & - & & 0.676 \\
\hline
\end{tabular}

\subsection{Bulk glass formation}

The thermal data obtained from the DTA and DSC analyses for $\mathrm{Fe}_{70-x} \mathrm{TM}(\mathrm{TM}=\mathrm{Mn}, \mathrm{Mo}, \mathrm{Ni}){ }_{13} \mathrm{~B}_{17} \mathrm{Y}_{x}(x=0,3$, 5 and 10) alloys are summarized in Table 1 . To evaluate the GFA, injection casting experiment was performed using $\mathrm{Cu}$ molds having cylindrical cavities with diameters of $1 \mathrm{~mm}$ and $2 \mathrm{~mm}$. Since the cooling rate is inversely proportional to the diameter of ingot, the maximum diameter for glass amorphous formation can be considered as a real parameter reflecting the GFA. The results of the injection casting experiment showed that $\mathrm{Fe}_{70-x} \mathrm{Mn}_{13} \mathrm{~B}_{17} \mathrm{Y}_{x} \quad(x=5)$ and $\mathrm{Fe}_{70-x} \mathrm{Mo}_{13} \mathrm{~B}_{17} \mathrm{Y}_{x}(x=3)$ alloys exhibited the best GFA in the alloy systems of $\mathrm{Fe}_{70-x} \mathrm{Mn}_{13} \mathrm{~B}_{17} \mathrm{Y}_{x}$ and $\mathrm{Fe}_{70-x^{-}}$ $\mathrm{Mo}_{13} \mathrm{~B}_{17} \mathrm{Y}_{x}$, respectively. Among $\mathrm{Fe}_{70-x} \mathrm{Ni}_{13} \mathrm{~B}_{17} \mathrm{Y}_{x}$ alloys, the alloy of $x=10$ showed the best glass forming ability.

Figures 2(c) and (d) show the DSC traces obtained from the injection cast $\mathrm{Fe}_{70-x} \mathrm{Mn}_{13} \mathrm{~B}_{17} \mathrm{Y}_{x}(x=5)$ bulk specimens with diameters of $1 \mathrm{~mm}$ and $2 \mathrm{~mm}$. The DSC trace of the injection-cast alloy with $1 \mathrm{~mm}$ diameter showed the glass 
Table 2 Thermodynamics parameters of melt-spun ribbons and injection cast bulk samples in the selected Fe-TM (Mn, Mo, Ni)-B-Y-alloy.

\begin{tabular}{cccccc}
\hline \multicolumn{1}{c}{ Alloy } & Specimen & $T_{\mathrm{g}}$ & $\begin{array}{c}T_{\mathrm{x}} \\
{[\mathrm{K}]}\end{array}$ & $\Delta T_{\mathrm{x}}$ & $\begin{array}{c}\Delta H_{\mathrm{x}} \\
{[\mathrm{J} / \mathrm{g}]}\end{array}$ \\
\hline $\mathrm{Fe}_{65} \mathrm{Mn}_{13} \mathrm{~B}_{17} \mathrm{Y}_{5}$ & Melt spun ribbon & 834.4 & 884 & 49.6 & -39 \\
& $\phi 1 \mathrm{~mm}$ & 833 & 872 & 39 & -38 \\
& $\phi 2 \mathrm{~mm}$ & - & 877 & - & -22.7 \\
$\mathrm{Fe}_{67} \mathrm{Mo}_{13} \mathrm{~B}_{17} \mathrm{Y}_{3}$ & Melt spun ribbon & 860.8 & 901.3 & 40.5 & -65.6 \\
& $\phi 1 \mathrm{~mm}$ & 865.8 & 906.7 & 40.9 & -63.3 \\
& $\phi 2 \mathrm{~mm}$ & - & 901.9 & - & -14.2 \\
$\mathrm{Fe}_{65} \mathrm{Ni}_{13} \mathrm{~B}_{17} \mathrm{Y}_{5}$ & Melt spun ribbon & - & 840 & - & -76.3 \\
& $\phi 1 \mathrm{~mm}$ & - & 830 & - & -4.0 \\
$\mathrm{Fe}_{60} \mathrm{Ni}_{13} \mathrm{~B}_{17} \mathrm{Y}_{10}$ & Melt spun ribbon & - & 931 & - & -63.7 \\
& $\phi 1 \mathrm{~mm}$ & - & 932.9 & - & -44 \\
\hline
\end{tabular}

transition and crystallization behavior similar to the result obtained from the melt-spun ribbon (Fig. 2(b)), i.e. the glass transition temperature and crystallization enthalpy $\left(\Delta H_{\mathrm{x}}\right)$ were almost same, although the crystallization onset temperature decreased by about $12 \mathrm{~K}$, as shown in Table 2 . The $\Delta H_{\mathrm{x}}$ of the first crystallization reaction for the $2 \mathrm{~mm}$ diameter injection-cast alloy, however, decreased significantly (Fig. 2(d)), indicating the formation of mixed structure of amorphous and crystalline phases due to insufficient cooling rate during solidification. The XRD pattern from the $1 \mathrm{~mm}$ diameter sample (Fig. 6(a)) showed a diffuse halo peak indicating an amorphous structure, but that from the $2 \mathrm{~mm}$ sample (Fig. 6(b)) showed sharp crystalline peaks from $\gamma$-Fe and $\mathrm{Fe}_{2} \mathrm{~B}$ superimposed on the diffuse halo peak.

Figures 4(c) and (d) show DSC traces obtained from the injection cast $\mathrm{Fe}_{70-x} \mathrm{Mo}_{13} \mathrm{~B}_{17} \mathrm{Y}_{x}(x=3)$ bulk specimens with diameters of $1 \mathrm{~mm}$ and $2 \mathrm{~mm}$. The DSC trace obtained from the injection-cast alloy with $1 \mathrm{~mm}$ diameter showed the glass transition and crystallization behavior similar to the result obtained from the melt-spun ribbon (Fig. 4(b)), as shown in Table 2. However, sample with the diameter of $2 \mathrm{~mm}$ showed

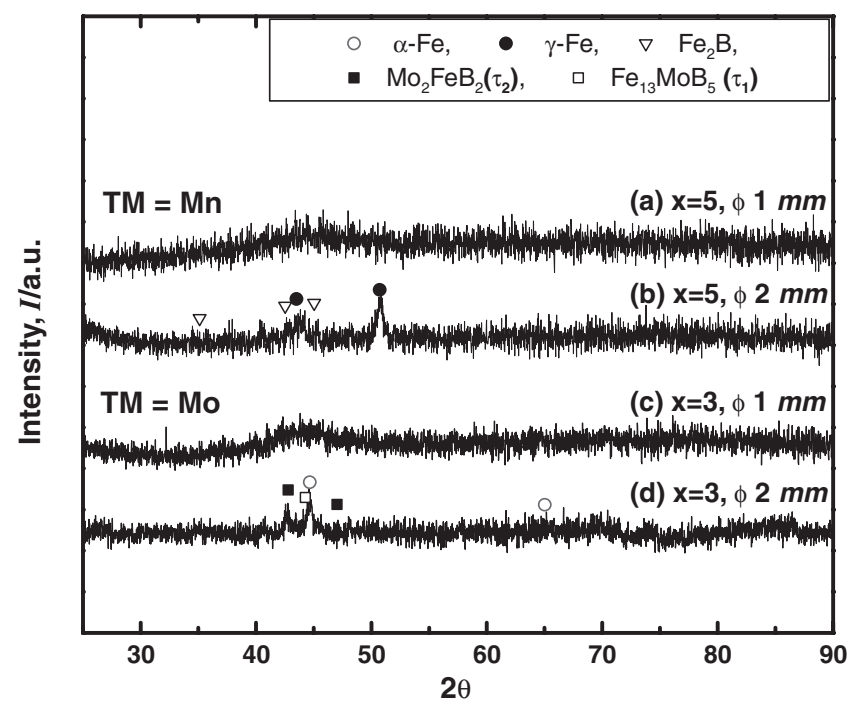

Fig. 6 XRD patterns taken from injection cast samples in $\mathrm{Fe}-\mathrm{TM}(\mathrm{Mn}$, Mo)-B-Y alloys. (a) and (b) $\mathrm{Fe}_{65} \mathrm{Mn}_{13} \mathrm{~B}_{17} \mathrm{Y}_{5}$, (c) and (d) $\mathrm{Fe}_{67} \mathrm{Mo}_{13} \mathrm{~B}_{17} \mathrm{Y}_{3}$. Here, (b) and (d) injection-cast sample with diameters of $2 \mathrm{~mm}$, and others are $1 \mathrm{~mm}$ in diameter. a significantly lower $\Delta H_{\mathrm{x}}$ value. The XRD pattern of the sample with the diameter of $1 \mathrm{~mm}$ (Fig. 6(c)) showed a diffuse halo peak indicating an amorphous structure, but that from the $2 \mathrm{~mm}$ sample (Fig. 6(d)) exhibited sharp crystalline peaks from the $\alpha-\mathrm{Fe}, \mathrm{Mo}_{2} \mathrm{FeB}_{2}$ and $\mathrm{Fe}_{13} \mathrm{Mo}_{2} \mathrm{~B}_{5}$ phases that were reported as stable crystalline phases in the Fe-Mo-B ternary system. ${ }^{9,10)}$

Figures 5(c) and (d) show the DSC traces obtained from the injection cast $\mathrm{Fe}_{70-x} \mathrm{Ni}_{13} \mathrm{~B}_{17} \mathrm{Y}_{x}(x=5,10)$ bulk specimens with the diameter of $1 \mathrm{~mm}$. The $\Delta H_{\mathrm{x}}$ was significantly small compared with that from the melt-spun ribbon, indicating that the glass forming ability was not sufficient to form the bulk sample with the diameter of $1 \mathrm{~mm}$.

\section{Discussion}

The present study clearly shows that the GFA improves when small amount of $\mathrm{Y}$ is added in Fe-TM-B alloy systems. Table 1 includes the parameter representing the glass forming ability, $\Delta T_{\mathrm{x}}\left(=T_{\mathrm{x}}-T_{\mathrm{g}}\right), T_{\mathrm{rg}}\left(=T_{\mathrm{g}} / T_{1}\right)$ and $\gamma\left(=T_{\mathrm{x}} /\left[T_{1}+\right.\right.$ $\left.\left.T_{\mathrm{g}}\right]\right)^{11,12)}$ for the alloys showing glass transition behavior. For $\mathrm{Fe}_{70-x} \mathrm{Ni}_{13} \mathrm{~B}_{17} \mathrm{Y}_{x}$ alloys, $T_{\mathrm{x}} / T_{\mathrm{L}}$ parameter is included, because the alloys do not show glass transition behavior. It is known that the $T_{\text {rg }}$ and $\gamma$ values for BMG formation in Febased system are larger than $\sim 0.6$ and $\sim 0.36$, respectively. ${ }^{11,12)}$ The $\mathrm{Fe}_{70-x} \mathrm{Mn}_{13} \mathrm{~B}_{17} \mathrm{Y}_{x}(x=5)$ and $\mathrm{Fe}_{70-x} \mathrm{Mo}_{13} \mathrm{~B}_{17} \mathrm{Y}_{x}$ $(x=3)$ alloys exhibiting high $T_{\mathrm{rg}}$ and $\gamma$ values (Table 1) have good glass forming ability enabling fabrication of $1 \mathrm{~mm}$ diameter BMG. For $\mathrm{Fe}_{70-x} \mathrm{Ni}_{13} \mathrm{~B}_{17} \mathrm{Y}_{x}$ alloys, the alloy with $x=10$ has the highest value of $T_{\mathrm{x}} / T_{\mathrm{L}}$ parameter, indicating that the glass forming ability improves with increasing $x$. It can be noted that the glass forming ability in Fe-TM-B-Y alloys improves, when the addition of $\mathrm{Y}$ decreases the melting temperature and, at the same time, increases the $T_{\mathrm{x}}$ and $T_{\mathrm{g}}$. For the case of Fe-Mo-B-Y alloys, it is probable that the improvement of GFA is influenced by the large increase of the $T_{\mathrm{x}}$ and $T_{\mathrm{g}}$ with increasing $\mathrm{Y}$ addition, thereby increasing the values of $T_{\mathrm{rg}}\left(=T_{\mathrm{g}} / T_{1}\right), \gamma\left(=T_{\mathrm{x}} /\left[T_{1}+T_{\mathrm{g}}\right]\right)$ and $T_{\mathrm{x}} / T_{\mathrm{L}}$, in spite of the increase of melting temperature (see Table 1).

The decrease in melting point and increase of $T_{\mathrm{x}}$ indicates that the liquid phase including glass state is stabilized with respect to competing crystalline phases. The stabilization of the liquid phase can be achieved by increasing the atomic packing density and by forming short-range compositional order in the liquid phase. ${ }^{13)}$ A large atomic size difference between $\mathrm{Y}$ and $\mathrm{Fe}, \mathrm{B}$ is favorable to increase the atomic packing density of the liquid structure. It has been reported that the Fe-TM-B and Fe-Ln(lanthanide)-B glassy alloys consist of unique network-like structures in which trigonal prism are connected densely with each other in an edgesharing mode through multi-bonding atoms of $\mathrm{Ln}$ and TM. ${ }^{14,15)}$ Especially, Nakamura et al. has pointed out that the prisms exhibit distorted shapes due to the atomic size difference between $\mathrm{TM}$ and $\mathrm{Fe}(\Delta r)$ through the X-ray scattering and EXAFS analyses, and also suggested that thermal stability of Fe-TM-B metallic glasses is attributed to the difficulty in rearranging the irregular structural units due to the presence of $\Delta r .^{14}$ )

The larger enthalpies of mixing between $\mathrm{Y}$ and $\mathrm{B}(-35 \mathrm{~kJ} /$ 
mol), compared to that between Fe and B $(-11 \mathrm{~kJ} / \mathrm{mol})$, can contribute to the stabilization of the liquid phase by changing the local atomic structure. Furthermore, the present study also indicated that the optimum $\mathrm{Y}$ content (maximum addition is 10 at $\%$ ) for improvement of GFA differently depends on the TM elements, i.e., 5 at $\%, 3$ at $\%$ and 10 at $\%$ for $\mathrm{Mn}, \mathrm{Mo}$ and $\mathrm{Ni}$, respectively. Based on the results of XRD analysis, it is concluded that competing crystalline phases in Fe-TM-B alloys differently depend on the alloy composition (TM and Y). As shown in Figs. 2 and 6, it is believed that the variation of the optimum $\mathrm{Y}$ content can originate from the different interactions between $\mathrm{Y}$ element and other components in the liquid alloys. Also, the different values of heat of mixing between $\mathrm{Y}$ and TM elements (i.e., Y-Mn: $-1 \mathrm{~kJ} / \mathrm{mol}$, Y-Mo: $24 \mathrm{~kJ} / \mathrm{mol}$ and Y-Ni: $-31 \mathrm{~kJ} / \mathrm{mol}$ ) would provide a different atomic bonding and thus a different geometrical network before solidification. However, in general, it is clear that the limited addition of Y in Fe-TM-B alloys improves the glass forming ability.

As can be seen in Table 1, the addition of $\mathrm{Y}$ atoms increases the crystallization onset temperature, improving the thermal stability of the amorphous phase. Figure 7 shows the influence of $\mathrm{Y}$ content on the crystallization onset temperature of the amorphous $\mathrm{Fe}_{70-x} \mathrm{TM}(\mathrm{TM}=\mathrm{Mn}, \mathrm{Mo}, \mathrm{Ni}){ }_{13} \mathrm{~B}_{17} \mathrm{Y}_{x}$ alloys. Interestingly, the variation of the crystallization onset temperature with addition of $\mathrm{Y}$ atoms shows a linear relationship, indicating that the addition of $\mathrm{Y}$ up to 10 at $\%$ in Fe-TM-B alloy system is strongly effective in improving the thermal stability of amorphous phase. In the present study, the thermal stability of the Fe-TM-B-Y amorphous phase with various heating rates is analyzed using Kissinger plot in which $\ln \left(\beta / T^{2}\right)$ versus $1 / T$ plot shows a linear relationship as shown in the following equation; ${ }^{16-19)}$

$$
\ln \left(\frac{\beta}{T^{2}}\right)=\frac{-E}{R T}+\ln \left(\frac{E K_{\mathrm{o}}}{R}\right)
$$

$(E$ : activation energy for nucleation and growth; $R$ : gas constant; $\beta$ : heating rate, $\left.t_{\mathrm{h}}=(T-298) / \beta\right)$ : time needed to reach $T ; K_{\mathrm{o}}$ : frequency factor)

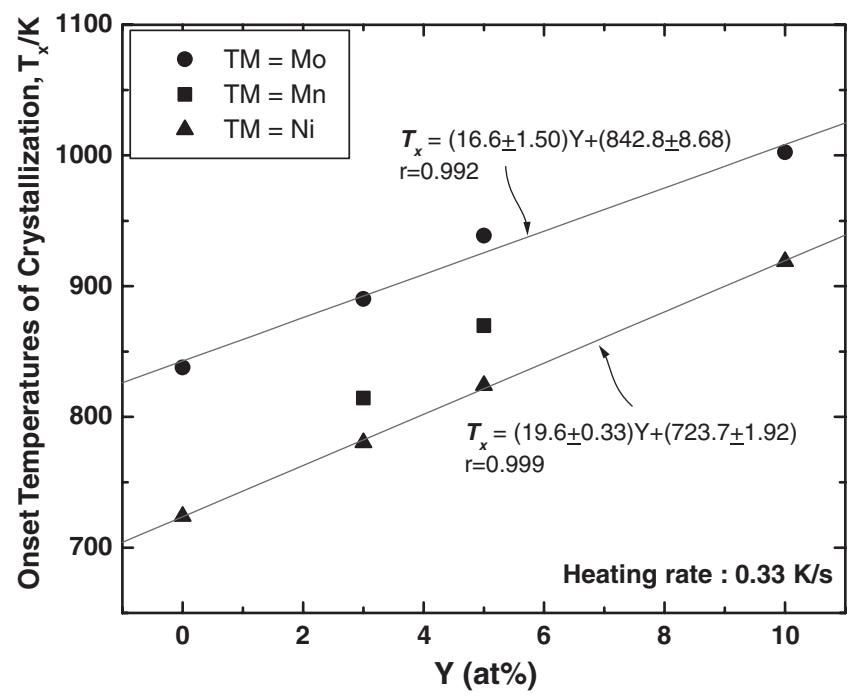

Fig. 7 Effect of $\mathrm{Y}$ contents on the thermal stability, represented by onset temperatures of crystallization, in the Fe-TM-B-Y alloy systems.
The crystallization rate constant $\left(K_{\mathrm{T}}\right)$ indicating the frequency for an atom having energy $E$ to join the cluster or nuclei at temperature $T$, can be obtained by Arrhenius equation, $K_{\mathrm{T}}=K_{\mathrm{o}} \exp (-E / R T)$. From eq. (1) $\beta$ at temperature $T$ can be calculated by;

$$
\beta=T^{2} \exp \left[\frac{-E}{R T}+C\right]
$$

where, $-E / R$ and $C\left(=\ln \left(E K_{\mathrm{o}} / R\right)\right)$ are the gradient and intercept value on the linear fit of the Kissinger plot, respectively. The underlying factors for this estimation are an identification of atomic frequency for nucleation and growth kinetics for crystallization $\left(e . g . K_{\mathrm{T}}\right)$. The use of the corollary of Kissinger analysis has been widely accepted and utilized for judging the relative thermal stability in terms of theoretical estimations, ${ }^{16,19)}$ since the obtained values from Kissinger analysis is comparable with those from other estimations. In general, peak temperature of crystallization $\left(T_{\mathrm{p}}\right)$ is used in Kissinger analysis to investigate the maximum transformation rate during crystallization of glass and to reduce the experimental error in temperature measurement by measuring the peak temperature. However, $T_{\mathrm{p}}$ can be substituted by onset temperature of crystallization $\left(T_{\mathrm{x}}\right)$ in order to calculate a continuous heating transformation curve for the devitrification of glass, which indicates an actual starting point (i.e., onset temperature and time) for the transformation from glass to crystalline phase under various heating rates. Using the experimental data from the DSC analysis obtained during heating with various heating rates $(0.167,0.333,0.667 \mathrm{~K} / \mathrm{s})$, the variation of crystallization onset temperature with heating time is calculated. Based on the linear relationship of $\ln \left(\beta / T_{\mathrm{x}}{ }^{2}\right)$ versus $1000 / T_{\mathrm{x}}, \mathrm{CHT}$ curves showing the relationship between $T_{\mathrm{x}}$ and corresponding heating time for the Fe-TM-B-Y alloys have been obtained using eq. 2 (see Fig. 8). The values of kinetic parameters needed for calculation are listed in Table 3. The correlation coefficient $(r)$ for regression is higher than 0.93 .

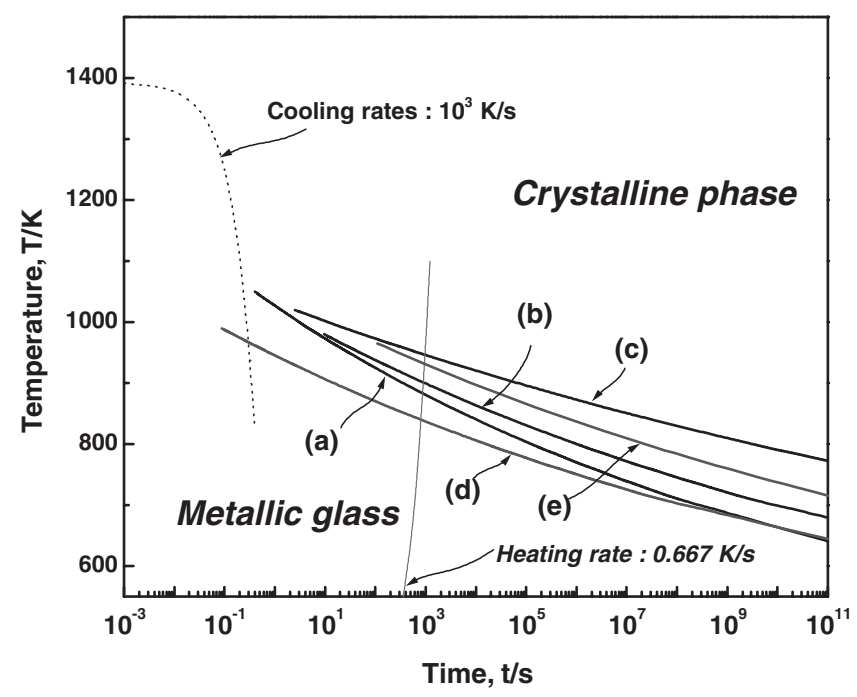

Fig. 8 CHT curves for the selected Fe-TM-B-Y glassy alloy derived by an extension of the Kissinger analysis ${ }^{14)}$ in which the thermal stability of the selected glassy alloys can be compared as a function of time. (a) $\mathrm{Fe}_{65} \mathrm{Mn}_{13} \mathrm{~B}_{17} \mathrm{Y}_{5}$, (b) $\mathrm{Fe}_{67} \mathrm{Mo}_{13} \mathrm{~B}_{17} \mathrm{Y}_{3}$, (c) $\mathrm{Fe}_{65} \mathrm{Mo}_{13} \mathrm{~B}_{17} \mathrm{Y}_{5}$, (d) $\mathrm{Fe}_{65} \mathrm{Ni}_{13}$ $\mathrm{B}_{17} \mathrm{Y}_{5}$, (e) $\mathrm{Fe}_{60} \mathrm{Ni}_{13} \mathrm{~B}_{17} \mathrm{Y}_{10}$. 
Table 3 Kinetics parameters for crystallization onset temperatures in the Fe-TM(Mn, Mo, Ni)-B-Y alloy ribbons.

\begin{tabular}{|c|c|c|c|c|c|c|c|}
\hline Alloys & $\begin{array}{c}T_{\mathrm{x}} \\
{[\mathrm{K}]}\end{array}$ & $-E / R$ & $C^{*}$ & $r$ & $\begin{array}{c}E \\
{[\mathrm{~kJ} / \mathrm{mol}]}\end{array}$ & $\begin{array}{c}K_{\mathrm{o}} \\
{\left[\mathrm{s}^{-1}\right]}\end{array}$ & Remarks \\
\hline $\mathrm{Fe}_{65} \mathrm{Mn}_{13} \mathrm{~B}_{17} \mathrm{Y}_{5}$ & 884 & -42108 & 33.73 & 0.93 & 350.1 & $1.868 \times 10^{19}$ & Fig. 8(a) \\
\hline $\mathrm{Fe}_{67} \mathrm{Mo}_{13} \mathrm{~B}_{17} \mathrm{Y}_{3}$ & 901.3 & -49932 & 41.11 & 0.93 & 415.1 & $4.961 \times 10^{22}$ & Fig. 8(b) \\
\hline $\mathrm{Fe}_{65} \mathrm{Mo}_{13} \mathrm{~B}_{17} \mathrm{Y}_{5}$ & 944.9 & -77355 & 67.66 & 0.96 & 643.1 & $1.867 \times 10^{34}$ & Fig. 8(c) \\
\hline $\mathrm{Fe}_{65} \mathrm{Ni}_{13} \mathrm{~B}_{17} \mathrm{Y}_{5}$ & 840 & -49991 & 45.67 & 0.99 & 415.6 & $3.409 \times 10^{24}$ & Fig. $8($ d) \\
\hline $\mathrm{Fe}_{60} \mathrm{Ni}_{13} \mathrm{~B}_{17} \mathrm{Y}_{10}$ & 931 & -56896 & 47.02 & 0.99 & 473.0 & $1.503 \times 10^{25}$ & Fig. 8(e) \\
\hline
\end{tabular}

Values of $T_{\mathrm{x}}$ were measured at a heating rate of $0.667 \mathrm{~K} / \mathrm{s}$.

* $C$ is defined by $\ln \left(E K_{\mathrm{o}} / R\right)^{\prime}$

Based on the current estimation, CHT curve for $\mathrm{Fe}_{65} \mathrm{Mn}_{13} \mathrm{~B}_{17} \mathrm{Y}_{5}$ alloy (Fig. 8(a)) exhibits larger curvature when compared with those of other CHT curves, indicating higher heating rate dependence of crystallization onset temperature due to smaller activation energy $(E)$ and frequency factor $\left(K_{\mathrm{o}}\right)$ i.e., lower temperature dependence of $K_{\mathrm{T}}$ (see Table 3 ). The thermal stability of glass against crystallization is mainly dependent on the required atomic mobility for nucleation and growth of a crystalline phase, especially at the temperature range near $T_{\mathrm{g}}$ and $T_{\mathrm{x}}$. For the case of linear heating, the lower atomic mobility and its lower temperature dependence suppresses the devitrification of glass, because a lager incubation time and higher temperature are required. Atomic mobility required for crystallization of glass is strongly dependent on the type of devitrification process (e.g., primary, polymorphous and eutectic-type transformation, etc.). In fact, Louzguine et al. have pointed out that the curvature of $\mathrm{CHT}$ curve (i.e., heating rate dependence of crystallization behavior), is closely related to the initial devitrification mechanism of glass. ${ }^{19)}$ In order to compare the thermal stabilities of Fe-TM-B-Y alloy glasses, further clarification of the initial devitrification mechanism is required. The CHT curves of $\mathrm{Fe}_{65} \mathrm{Mo}_{13} \mathrm{~B}_{17} \mathrm{Y}_{5}$ and $\mathrm{Fe}_{60} \mathrm{Ni}_{13}-$ $\mathrm{B}_{17} \mathrm{Y}_{10}$ alloys (Figs. 8(c) and (e)) are located at higher temperatures and slower delayed times, compared with those for $\mathrm{Fe}_{67} \mathrm{Mo}_{13} \mathrm{~B}_{17} \mathrm{Y}_{3}$ and $\mathrm{Fe}_{65} \mathrm{Ni}_{13} \mathrm{~B}_{17} \mathrm{Y}_{5}$ alloys (Figs. 8(b) and (d)), respectively. It is indicated that the glass alloy at higher temperature region of the CHT curves show higher thermal stability compared with those at lower temperature region. Therefore, it is noted that the addition of $\mathrm{Y}$ is effective in suppressing the devitrification of the amorphous structure in the Fe-TM-B-Y system during heating.

\section{Conclusion}

The glass forming ability improves when small amount of $\mathrm{Y}$ is added in $\mathrm{Fe}_{70} \mathrm{TM}(\mathrm{TM}=\mathrm{Mn}, \mathrm{Mo}, \mathrm{Ni})_{13} \mathrm{~B}_{17}$ alloys. $\mathrm{Fe}_{70-x} \mathrm{Mn}_{13} \mathrm{~B}_{17} \mathrm{Y}_{x} \quad(x=5)$ and $\mathrm{Fe}_{70-x} \mathrm{Mo}_{13} \mathrm{~B}_{17} \mathrm{Y}_{x} \quad(x=3)$ alloys exhibit high $T_{\mathrm{rg}}(>0.55)$ and $\gamma(>0.37)$ values enabling fabrication of $1 \mathrm{~mm}$ diameter BMG. For $\mathrm{Fe}_{70-x} \mathrm{Ni}_{13} \mathrm{~B}_{17} \mathrm{Y}_{x}$ alloys, the $T_{\mathrm{x}} / T_{\mathrm{L}}$ value increases with increasing $x$, indicating an improvement of glass forming ability. The glass forming ability improves when addition of $\mathrm{Y}$ decreases the melting temperature, and, at the same time, increases the crystallization onset temperature and glass transition temperature. Extended Kissinger analysis of the DSC data indicates that a kinetic boundary for the formation of the amorphous phase widens by addition of $\mathrm{Y}$.

\section{Acknowledgements}

The authors are grateful for the financial support of the Creative Research Initiatives of the Korean Ministry of Science and Technology. Also, the authors appreciate the reviewer's constructive comments.

\section{REFERENCES}

1) A. Inoue, T. Zhang and A. Takeuchi: App. Phy. Lett. 71 (1997) 464466.

2) V. Ponnambalam, S. J. Poon, G. Y. Shiflet, V. M. Keppens, R. Taylor and G. Petculescu: App. Phy. Lett. 83 (2003) 1131-1133.

3) T. D. Shen and R. B. Schwarz: App. Phy. Lett. 75 (1999) 49-51.

4) A. Inoue, A. Takeuchi and B. Shen: Mater. Trans. 42 (2001) 970-978.

5) P. Pawlik, H. A. Davies and M. R. J. Gibbs: App. Phy. Lett. 83 (2003) 2775-2777.

6) Y. C. Jung and K. Nakai: Metall. Mater. Int. 9 (2003) 337-344.

7) Z. P. Lu, C. T. Liu and W. D. Porter: App. Phy. Lett. 83 (2003) 25812583.

8) F. R. de Boer, R. Boom, W. C. M. Mattens, A. R. Miedema and A. K. Niessen: Cohesion in Metals; Transition Metal Alloys, (Elsevier Science Pub. B. V., 1988).

9) V. Raghavan: Phase Diagrams of Ternary Iron Alloys, (Indian Inst. Met., 1992) pp. 365.

10) V. Raghavan: Phase Diagrams of Ternary Iron Alloys, (Indian Inst. Met., 1992) pp. 387.

11) Z. P. Lu, T. T. Goh, Y. Li and S. C. Ng: Acta Mater. 47 (1999) 22152224.

12) Z. P. Lu and C. T. Liu: Acta Mater. 50 (2002) 3501-3512.

13) E. S. Park, H. K. Lim, W. T. Kim and D. H. Kim: J. Non-Cryst. Solids 298 (2002) 15-22.

14) T. Nakamura, E. Matsubara, M. Imafuku, H. Koshiba, A. Inoue and Y. Waseda: Mater. Trans. 42 (2001) 1530-1534.

15) A. Inoue and A. Takeuchi: Mater. Sci. \& Eng. A375-377 (2004) 16-30.

16) D. V. Louzguine and A. Inoue: Appl. Phy. Lett. 81 (2002) 2561-2562.

17) H. E. Kissinger: J. Res. Natl. Bur. Stand. 57 (1956) 217.

18) L. C. Chen and F. Spaepen: J. Appl. Phys. 69 (1991) 679-688.

19) D. V. Louzguine and A. Inoue: Scr. Mater. 47 (2002) 887-891. 